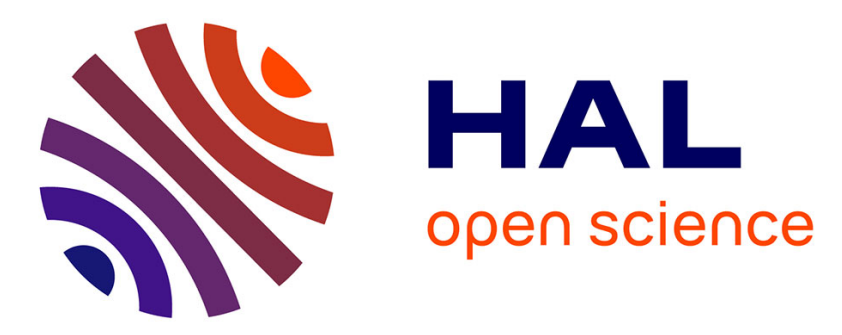

\title{
Feasibility of manufacturing of Al2O3-Mo HTCC by hybrid additive process
}

Mégane Bernard, Vincent Pateloup, Damien Passerieux, Dominique Cros, Valérie Madrangeas, Thierry Chartier

\section{- To cite this version:}

Mégane Bernard, Vincent Pateloup, Damien Passerieux, Dominique Cros, Valérie Madrangeas, et al.. Feasibility of manufacturing of Al2O3-Mo HTCC by hybrid additive process. Ceramics International, 2022, 10.1016/j.ceramint.2022.01.354 . hal-03578784

\section{HAL Id: hal-03578784 \\ https://hal-unilim.archives-ouvertes.fr/hal-03578784}

Submitted on 17 Feb 2022

HAL is a multi-disciplinary open access archive for the deposit and dissemination of scientific research documents, whether they are published or not. The documents may come from teaching and research institutions in France or abroad, or from public or private research centers.
L'archive ouverte pluridisciplinaire HAL, est destinée au dépôt et à la diffusion de documents scientifiques de niveau recherche, publiés ou non, émanant des établissements d'enseignement et de recherche français ou étrangers, des laboratoires publics ou privés. 


\section{Feasibility of manufacturing of $\mathrm{Al}_{2} \mathrm{O}_{3}-\mathrm{Mo} \mathrm{HTCC}$ by hybrid additive process}

Mégane Bernard ${ }^{\mathrm{a}}$, Vincent Pateloup a , Damien Passerieux ${ }^{\mathrm{b}}$, Dominique Cros ${ }^{\mathrm{b}}$, Valérie Madrangeas ${ }^{\mathrm{b}}$, Thierry Chartier ${ }^{\mathrm{a}}$

a CNRS, University of Limoges, Institute of Research for Ceramics (IRCER), UMR 7315, Limoges, France

${ }^{\mathrm{b}}$ CNRS, University of Limoges, XLim, UMR 7252, Limoges, France

Keywords: stereolithography, robocasting, hyperfrequency, additive manufacturing

\section{$\underline{\text { Abstract }}$}

Additive manufacturing processes make it possible to produce increasingly complex 3D parts. In addition, these numerical processes can be usefully used to manufacture ceramic/metal parts of high dimensional resolution with thermal, electrical and electronic properties of interest for applications in the field of power electronics.

In this context, a hybrid additive machine was developed to manufacture ceramic/metal parts. This machine consists in the combination of two additive manufacturing processes: stereolithography and robocasting.

Using this hybrid process, the feasibility of HTCC components has been demonstrated by building dielectric alumina by stereolithography and molybdenum conductive network by robocasting. Molybdenum-based metallic formulation adapted to the process and allowing to obtain a high conductive metallic network has been developed. The co-debinding and cosintering cycles have been optimized to minimize the content of residual carbon and to prevent the oxidation of molybdenum. The alumina/molybdenum interface has also been observed to conclude about a possible delamination between these two materials with different thermal expansion coefficients (CTE). Sintered HTCC parts have been characterized in the domain of hyperfrequency. The frequency responses deviate from the simulation due to a lack of dimensional accuracy of the metallic network. 


\section{I.1 Introduction}

In the field of microelectronics, a particular interest is focused on the use of "Temperature Co-Fired Ceramics" (TCC) elaborated using multilayer technologies. These technologies appear in the early 90s in order to develop 3D components for many applications. TCC components consist in a stack of several dielectric ceramic layers with printed metallic patterns, assembled and co-fired. Conductive metallic tracks can be horizontal or vertical (vias). Co-firing (co-sintering) are performed at high temperature $\left(\mathrm{T}>1000^{\circ} \mathrm{C}\right)$ in the case of High Temperature Co-Fired Ceramics (HTCC) or at low temperature $\left(\mathrm{T} \leq 1000^{\circ} \mathrm{C}\right)$ for Low Temperature Co-Fired Ceramics (LTCC). The choice between HTCC and LTCC will depend on the conditions of use of the components. For instance, in the case of spatial applications, HTCC are preferred due to the atmosphere of use while, for less severe conditions, this will be LTCC [1]. In the case of HTCC, the dielectric substrate is commonly composed of alumina and the conductive tracks part is based on tungsten or molybdenum metal [2], [3]. Concerning LTCC, a mixture of glass and alumina is generally found in the substrate while metal is gold, silver or copper. The characteristics of the glass and the substrate composition, then the sintering temperature, will depend on the application.

HTCC and LTCC components are conventionally elaborated by tape casting for the dielectric substrate and screen-printing for the conductive tracks and vias. The main limitations of these processing routes are:

- The critical drying of tapes which can cause cracks and warping [4],

- A minimum thickness of the tape-cast green sheets of about $150 \mu \mathrm{m}$, necessary for subsequent operations [1], e.g. manipulation, screen-printing, punching, stacking, lamination...,

- The drying time required between the different metal screen-printed stages to reach a sufficient track thickness of $40 \mu \mathrm{m}$,

- The limitation in the complexity of the metallic conductive network embedded in the dielectric substrate that can restrict the electrical functions and performances of the TCC component.

In this context, it appears interesting to develop a new processing route which makes it possible to overcome these limitations and therefore to allow the manufacture of more complex components having new functions and/or improved performances. In this respect, an 
innovative hybrid machine consisting in the association of two additive manufacturing (AM) technologies has been developed in previous works by Raynaud et al. [5], [6]. AM technologies bring a significant increase in industry because it allows to produce faster complex shapes that cannot be realized with conventional routes, while minimizing waste [7], [8].

Sealy et al. [9] define hybrid additive manufacturing processes as "the use of additive manufacturing with one or more secondary process or energy sources that are fully coupled and synergistically affect part quality, functionality, and/or process performance." The approach proposed is a hybridization of the stereolithography process for manufacturing the alumina dielectric substrate and robocasting for the deposition of the metallic conductive network. The objective of this process is to benefit from an automated process, starting from the CAD file of the component whose properties have, for example, been optimized by numerical modeling, to build more complex 3D metal circuits, more complex ceramic packaging shapes and to decrease the thickness of each layer in comparison to conventional tape-casting/screen-printing route.

This article focuses on the elaboration of HTCC parts with different geometries composed of alumina for the dielectric substrate and molybdenum for conductive tracks and vias. The industrial targets and our objectives in terms of layers and track dimensions are presented in Table 1. The extrusion nozzle has a $100 \mu \mathrm{m}$ diameter, and then the width of the metal tracks is expected to be about $150 \mu \mathrm{m}$ according to the spreading of the molybdenum ink. It is planned, in the future, to work with a smaller nozzle (i.e. $50 \mu \mathrm{m}$ ), which will likely require the adaptation of the ink formulation.

Table 1: Industrial targets and expected dimensions in this work

Industrial targets

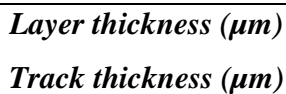

Track width $(\mu \mathrm{m})$

\begin{tabular}{c|cc}
\hline Layer thickness $(\boldsymbol{\mu m})$ & $10-50$ & 50 \\
Track thickness $(\boldsymbol{\mu m})$ & 40 & $30-40$ \\
Track width $(\boldsymbol{\mu m})$ & 80 & 150
\end{tabular}

Expected dimensions in this work

Previous works, and those of J. Raynaud [1], [5], [10], have shown that the use of tungsten presents some limitations. Indeed, in addition to a moderate electrical conductivity $\left(\sigma_{\mathrm{W}}=8.9 .10^{6} \mathrm{~S} . \mathrm{m}^{-1}\right)$, delamination at the ceramic/metal interfaces were observed due to a high difference of Coefficient of Thermal Expansion (CTE) between tungsten (CTE $=4,4.10^{-6} \mathrm{~K}^{-1}$ ) 
and alumina $\left(\mathrm{CTE}=7.110^{-6}{ }^{\circ} \mathrm{C}^{-1}\right)$. Then the tungsten is here replaced by molybdenum with an electrical conductivity of $\sigma_{M o}=18.7 \cdot 10^{6} \mathrm{~S} \mathrm{~m}^{-1}$ and a CTE $=5.35 .10^{-6 \circ} \mathrm{C}^{-1}$.

The debinding performed under reducing atmosphere to prevent oxidation of molybdenum present the drawback of leaving a significant amount of residual carbon, which can be detrimental to the dielectric properties of the ceramic. In this respect, the debinding thermal cycle and atmosphere were optimized. Only few studies have reported such an optimization of the debinding. The addition of water is performant to improve the removal of residual carbon without oxidizing the metal.

\section{I.2 Materials and methods}

\section{I.2.1 Hybrid additive process}

The hybrid process developed is a combination of two additive manufacturing technologies, where each one has an essential role to produce multi-material parts. The stereolithography process is used to build the ceramic dielectric part layer by layer, whereas the robocasting process is used to deposit the metal tracks/vias. Additive manufacturing processes are based on a CAD file of the part to build. The CAD file is converted into a .STL file format, which is a standard interface between 3D CAD models and the additive system. Then, the 3D model is decomposed into cross-sectional layers and the conditions are generated to physically build up the cross-sectional patterns in each layer. These conditions are for instance, in the case of stereolithography, the power and velocity of the laser and the hatch spacing (distance between two lasing lines). After the fabrication of the green part using the stereolithography process, post-treatment steps are required: cleaning to remove residual non-polymerized suspension sticking to the surface of the part, debinding and sintering.

The stereolithography is based on the polymerization of a reactive system under the effect of a light source, usually an ultraviolet laser source [11]. The curable suspension is spread on the working surface with a layer thickness corresponding to the cross-sectional layer of the .STL file. Then, each cross-sectional pattern in the considered plane is polymerized thanks to the $\mathrm{X} / \mathrm{Y}$ deflection of a UV laser beam (wavelength of $355 \mathrm{~nm}$ in this study) (Figure 1.a)). The reactive system consists in a suspension of ceramic particles in a curable monomer and/or oligomer with the addition of a photoinitiator [12]. 
Robocasting consists in the deposition of a filament of paste extruded through a nozzle by applying a pressure or using a screw [13], [14]. The developed hybrid additive machine uses a robocasting head installed on a robotic arm (6 axis). The nozzle diameter is $100 \mu \mathrm{m}$ and the positioning accuracy of the robotic arm is around 20 microns. The extrusion of a metallic ink will allow the deposition of conductive tracks and the filling of the vias (Figure 1.b)).



a)

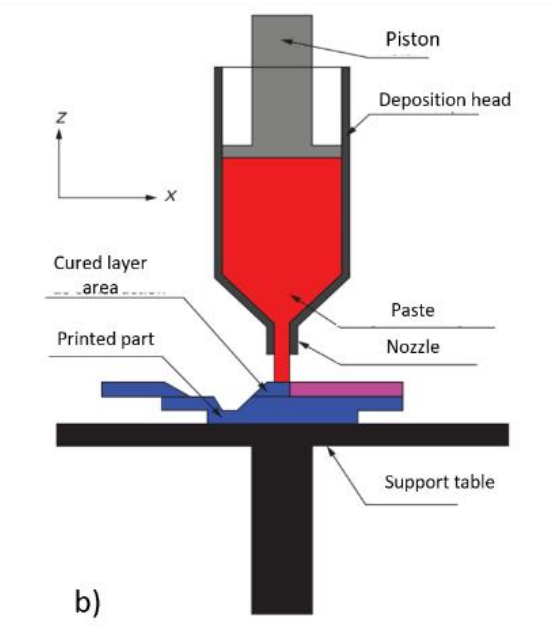

Figure 1: Principle of the processes of Stereolithography a) and Robocasting b) [15], [16]

The hybrid machine developed (Figure 2.a)) associates a stereolithography equipment to build the 3D alumina dielectric substrates (Figure 2.b)) with a robotic arm supporting a robocasting head to print the molybdenum conductive network (Figure 2.c)). In order to avoid the tearing of the metal track during the deposition of the subsequent ceramic layer, the latter is not deposited in excess thickness onto the surface of the ceramic layer. The uncured part of the substrate corresponding to the metallic pattern is sucked up and the metallic paste is then deposited in the trench thus created. The same procedure is applied to the vias.
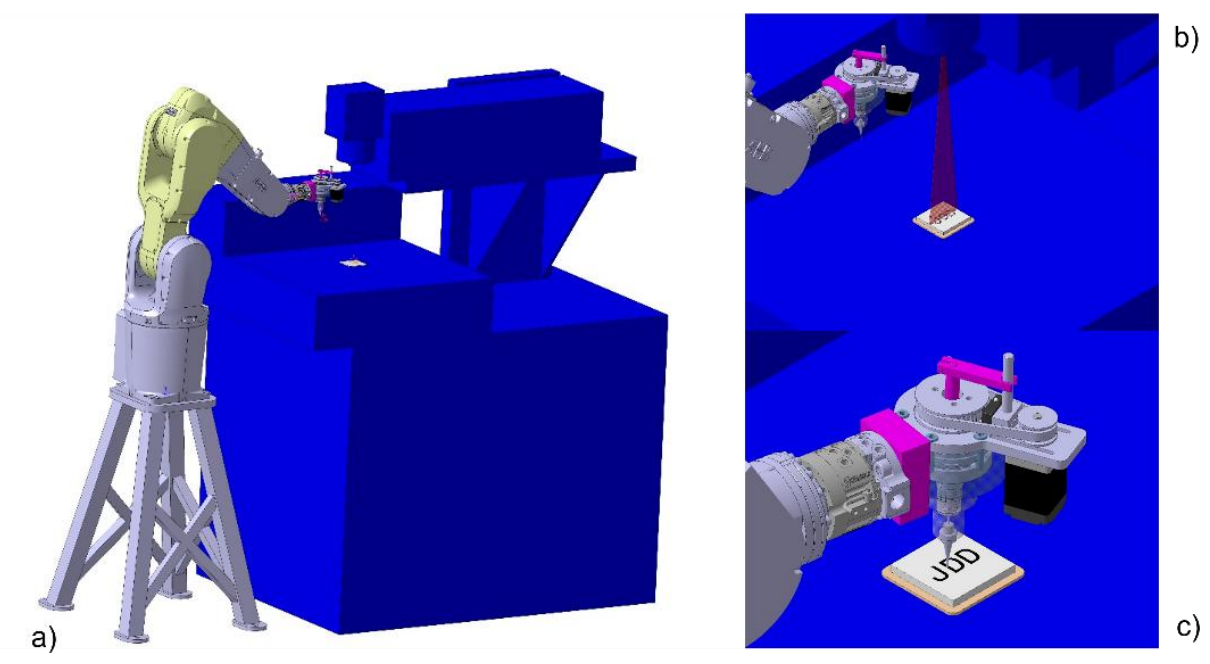

Figure 2: Hybridization of stereolithography and robocasting processes 
The feasibility of manufacturing HTCC alumina/molybdenum components with different geometries has been evaluated using this hybrid additive equipment.

A simple geometry consists in the deposition of a molybdenum track (with a thickness of about $50 \mu \mathrm{m}$ ) onto an alumina substrate, composed of a sequence of $50 \mu \mathrm{m}$ layers, (Figure 3.a)). This track is covered with alumina layers on which a new layer of metal is deposited on the surface. Thereby, it is possible to observe the morphology and dimensions of the upper track after co-sintering and to measure their electrical conductivity. The lower track, embedded into alumina, allows the observation of molybdenum/alumina interfaces after cosintering.
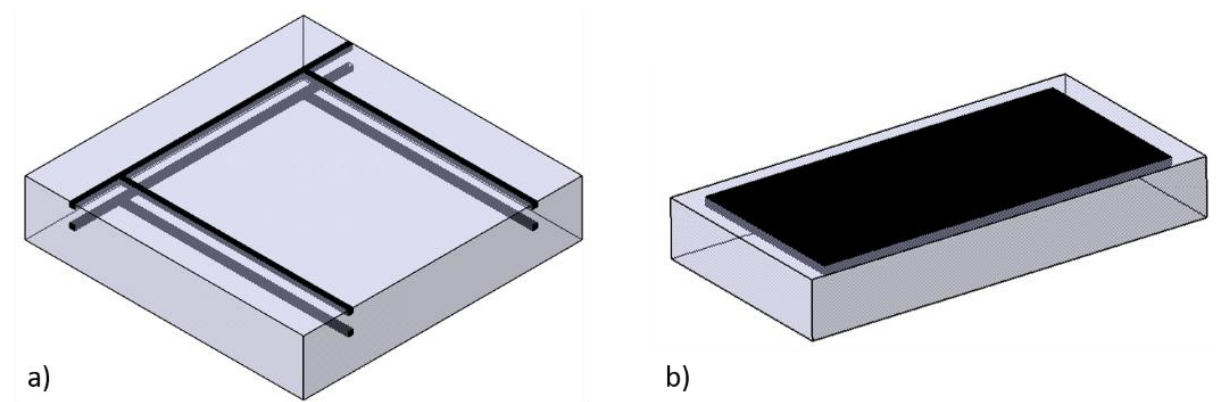

b)

Figure 3: Presentation of the simple geometry used to measure the electric conductivity and to observe eventual delamination between molybdenum (black) and alumina (grey) a) and to observe the alumina/molybdenum interface b)

Another simple geometry (Figure 3.b)) is fabricated to observe alumina/metal interface by Focused Ion Beam microscopy (FIB). This second geometry consists of a metallic plane deposited on the surface of an alumina substrate.

\section{I.2.2 Starting materials and metallic ink}

The dielectric substrate must present various characteristics:

- A low relative permittivity, that represents the response of a material to an electromagnetic field, to ensure a good insulation, typically, between 9 and 10 [5],

- A low coefficient of temperature (variation of the permittivity with temperature) to ensure stable performances of the component, in operation [17], $\varepsilon=1.1 .10^{1}$ between 0 and $600{ }^{\circ} \mathrm{C}$ for a frequency between $120 \mathrm{~Hz}$ and $1 \mathrm{MHz}$,

- A low dielectric loss ( $\tan \delta$ ), between $10^{-3}$ and $10^{-4}$ at $10-15 \mathrm{GHz}$,

- A sufficient thermal conductivity to allow a good dissipation of the heat generated by the flow of current, typically around $20 \mathrm{~W} \cdot \mathrm{m}^{-1} \cdot{ }^{\circ} \mathrm{C}^{-1}$ at $20^{\circ} \mathrm{C}$. 
Although, the literature concerning HTCC reported zirconia, mullite, cordierite or beryllium oxide as substrate materials [11], [18], alumina is a good candidate as this material fulfills required characteristics given above (Table 2). Indeed, alumina presents some interesting properties such as:

- a significant ability to dissipate heat due to its high thermal conductivity in comparison to organic substrates,

- a coefficient of thermal expansion close to that of microchip, which will increase the reliability of the components [1],

- a high hardness, a high modulus of elasticity (i.e., about $380 \mathrm{GPa}$ ), a high resistance to rupture (i.e. about $350 \mathrm{MPa}$, flexion) as well as,

- refractory properties [19].

Alumina used is the P172LSB grade from Altéo (France) with a mean particle size of 0.40 $\mu \mathrm{m}$, a specific surface area $8.0 \mathrm{~m}^{2} / \mathrm{g}(\mathrm{BET})$ and a purity of $99.8 \%$.

Table 2: Alumina characteristic according to HTCC applications

\begin{tabular}{|c|c|c|c|c|}
\hline Properties & $\begin{array}{c}\text { Thermal } \\
\text { conductivity } \\
\left(W \cdot m^{-1} \cdot K^{-1}\right)\end{array}$ & $\begin{array}{l}\text { Coefficient of thermal } \\
\text { expansion }\left(10^{-6}{ }^{\circ} \mathrm{C}^{-1}\right)\end{array}$ & $\begin{array}{c}\text { Relative } \\
\text { permittivity (10- } \\
15 \mathrm{GHz})\end{array}$ & $\begin{array}{r}\text { Dielectric loss } \\
(10-15 \mathrm{GHz})\end{array}$ \\
\hline Alumina & 18 & 7.1 & 9.4 & 0.001 \\
\hline
\end{tabular}

The reactive system adapted to the stereolithography process is composed of reactive resin, typically a mixture of oligomers and/or monomers, a dispersant, a photoinitiator and the alumina powder. This curable paste is commercialized by 3D Ceram-Sinto, Limoges (France) meeting the necessary criteria outlined below:

- a shear thinning rheological behavior (Figure 4),

- a high reactivity at $355 \mathrm{~nm}$ (cure depth $=150 \mu \mathrm{m}$ for an energy density $=60 \mathrm{~mJ} / \mathrm{mm}^{2}$ )

- a powder loading of $57 \% \mathrm{vol}$,

- a good state of dispersion (no agglomerates). 


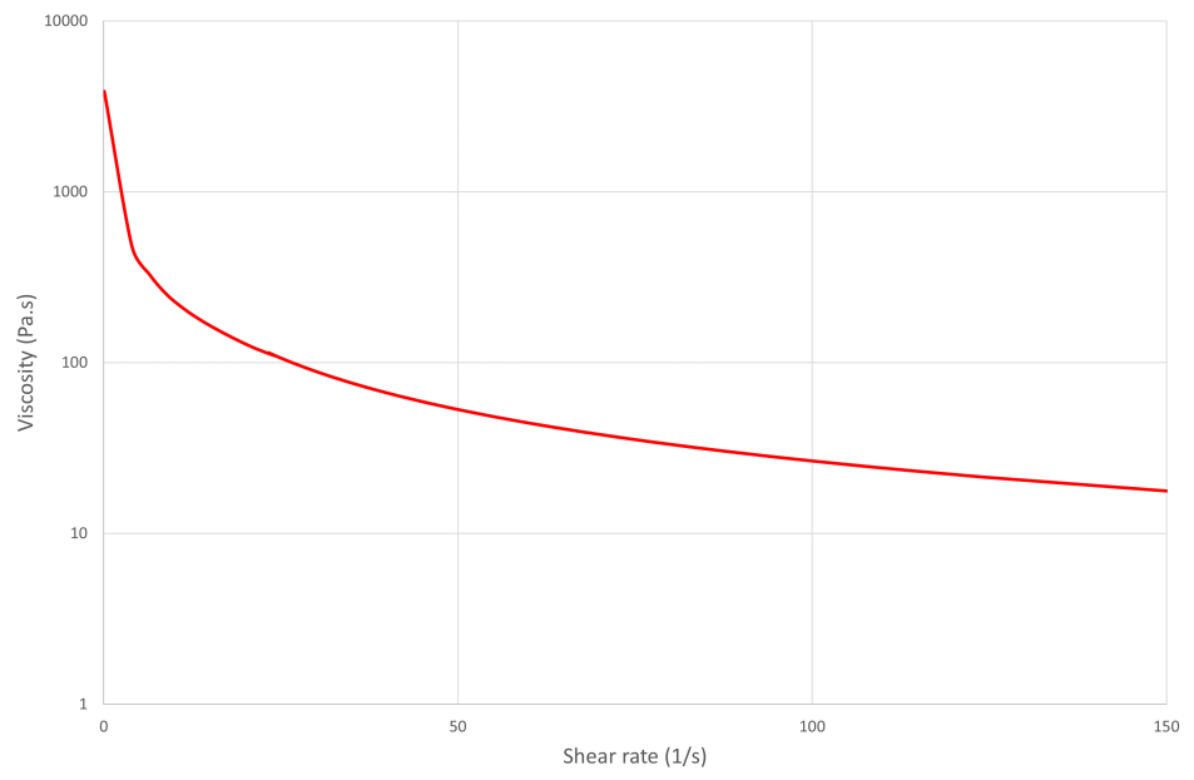

Figure 4: Rheogram of the 3D Ceram-Sinto alumina paste

The literature concerning HTCC components generally reported the use of tungsten as metallic conductor [1], [5]. According to its higher electrical conductivity and CTE (closer to alumina one reducing the risk of delamination at the ceramic/metal interface), molybdenum

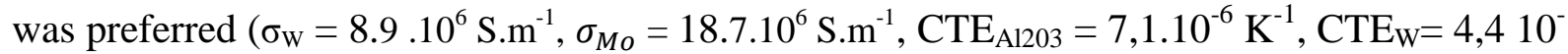
${ }^{6} \mathrm{~K}^{-1}$ and $\mathrm{CTE}_{\mathrm{Mo}}=5,35 \cdot 10^{-6} \mathrm{~K}^{-1}$ ).

A molybdenum powder with a mean grain size of about $3 \mu \mathrm{m}$ (Sigma-Aldrich, USA), suitable

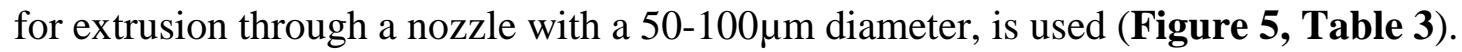

Table 3: Characteristics of the molybdenum powder

\begin{tabular}{c|ccc} 
Reference Sigma-Aldrich & $\boldsymbol{d}_{\mathbf{5 0}}(\boldsymbol{\mu m})$ & Density $\left(\mathbf{g} / \mathrm{cm}^{\mathbf{3}}\right)$ & Specific surface BET $\left(\mathrm{m}^{2} / \mathbf{g}\right)$ \\
\hline 051192 & 2.98 & 9.72 & 2.13
\end{tabular}



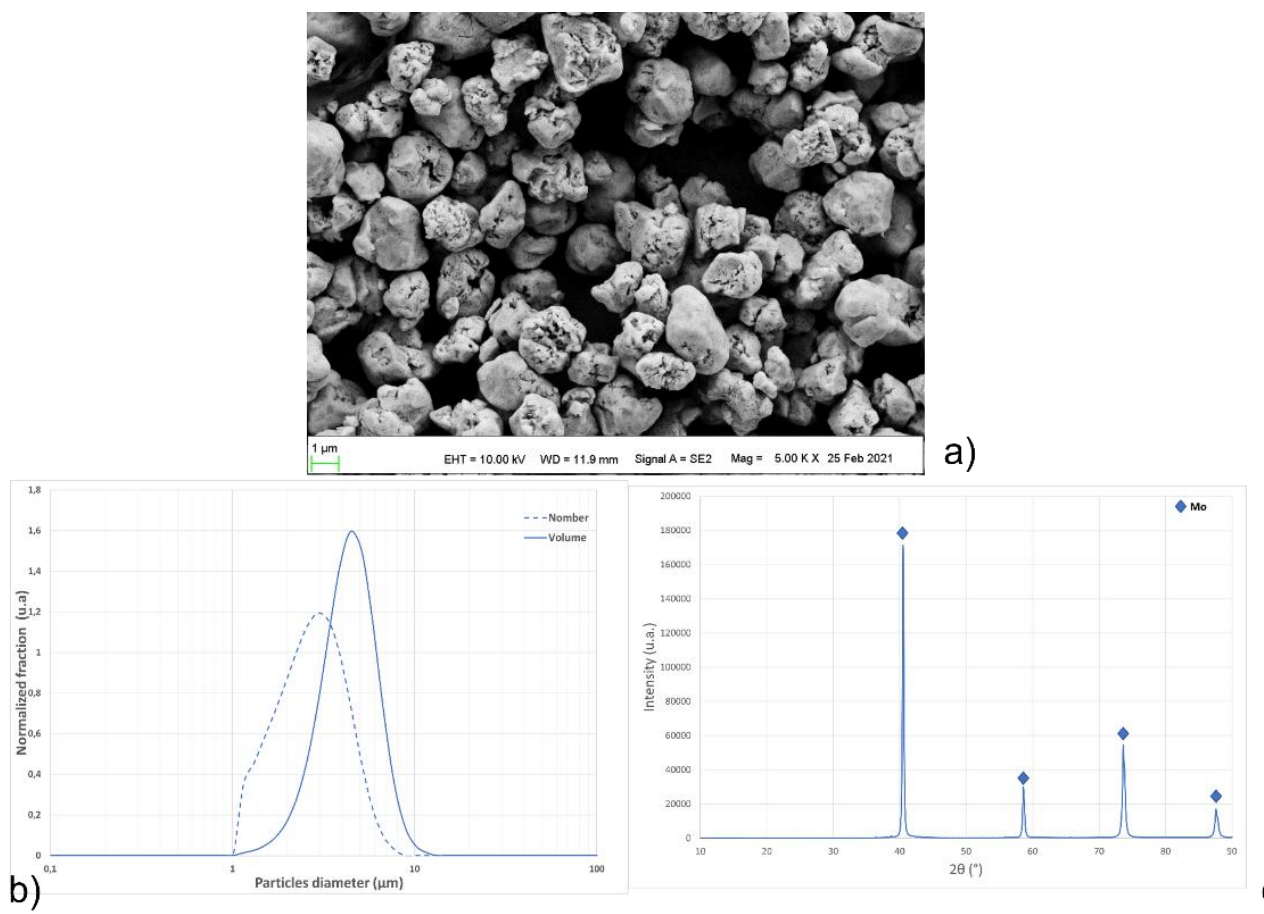

c)

Figure 5: Micrograph of the molybdenum powder a), particle size distribution b) and diffractogram c)

A formulation of molybdenum ink adapted, in terms of rheology, to the extrusion through a nozzle with a diameter between $100 \mu \mathrm{m}$ has been developed.

This ink is composed of:

- $\quad$ solvent (2,2,4-Trimethylpentane-1,3-diol-monoisobutyrate) (12.2 vol\%),

- $\quad$ binder (48.7 vol\%),

- dispersant (0.2 to $1.4 \mathrm{~m} \%$ on the molybdenum powder basis)

- molybdenum powder (39 vol\%).

The binder is a derivative of cellulose, which confers suitable rheological properties for extrusion, avoids filter-pressing in the nozzle and allows the filament to remain cohesive during the evaporation of the solvent [6]. The dispersant is necessary to allow a good state of dispersion of the powder in the suspensive media.

\section{I.3 Results and discussion}

\section{I.3.1 Molybdenum ink}

To reach the best state of dispersion on molybdenum particles in the metallic ink, the amount of dispersant was optimized. Different dispersant amounts ranging from 0.2 to $1.4 \mathrm{~m} \%$ on the metal powder basis have been tested (Figure 6). The lower viscosity for a shear rate of $200 \mathrm{~s}^{-1}$ 
is obtained for an amount of dispersant of $0.4 \% \mathrm{~m}$. This shear rate corresponds to the shear gradient imposed during the extrusion of the paste through a $100 \mu \mathrm{m}$ nozzle.

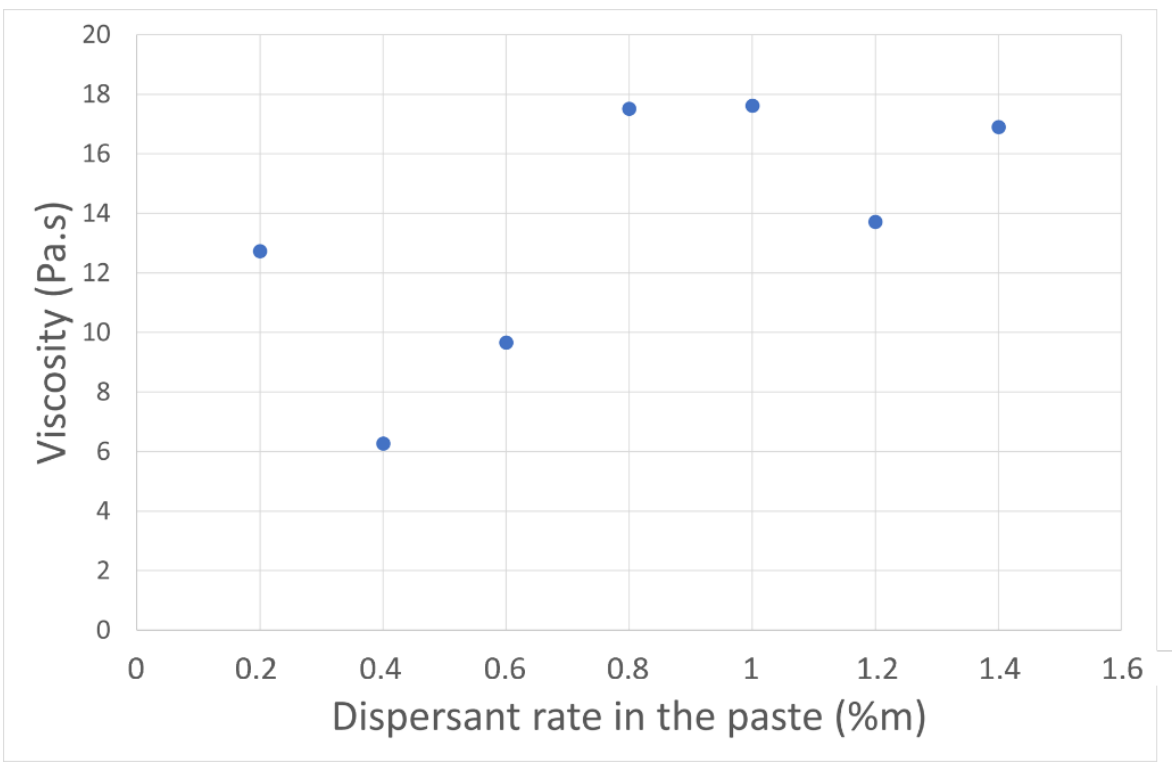

Figure 6: Rheological study of the influence of the dispersant amount in the metallic ink with the viscosity as a function of the dispersant amount at $200 \mathrm{~s}^{-1}$, which corresponds to the shear gradient imposed during extrusion

A phenomenon of drop at the beginning of the strip was observed, in the previous works [10] using tungsten ink, generating a detrimental non-constant width of the strip (Figure 7.a)). The higher viscosity of the molybdenum ink, in comparison to the tungsten one (Figure 7.b)), remains adapted to the extrusion through a $100 \mu \mathrm{m}$ diameter nozzle but offer the advantage to avoid the formation of undesirable drops at the beginning of the strip.

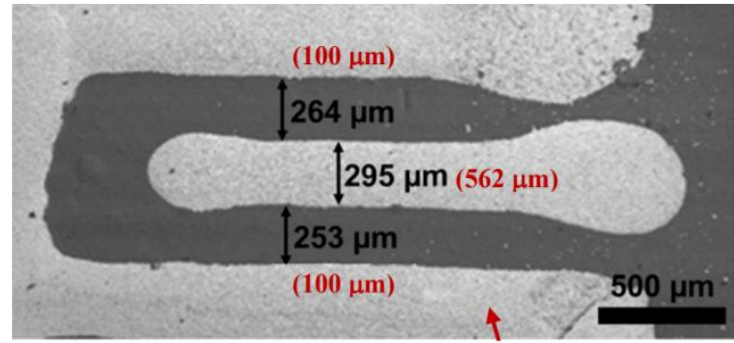

a)

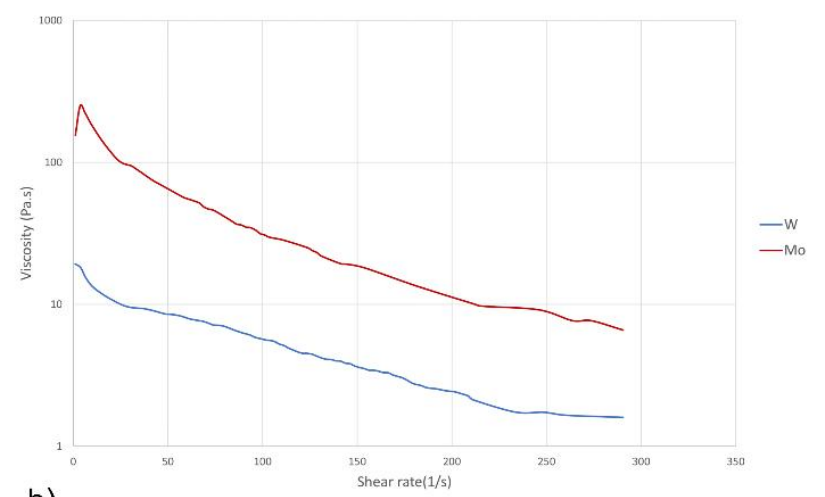

b)

Figure 7: Micrograp of strip with the observed drop phenomenon for the tungsten ink [10] a) and Rheological comparison of tungsten (blue) and molybdenum (red) b) 


\section{I.3.2 Thermal treatments}

Both the alumina stereolithography system and the molybdenum ink contain organic additives, respectively 40 and $61 \mathrm{vol} \%$. Organic components have to be totally extracted prior sintering, in a debinding stage, without any cracking, deformation or delamination of the ceramic/metal green part. In order to define a suitable debinding cycle, thermogravimetric analysis associated with differential thermal analysis (Labsys-evo-1600, Setaram, France) were performed both on alumina and molybdenum systems under $\mathrm{Ar} / 2 \mathrm{wt} \% \mathrm{H}_{2}$. The presence of molybdenum in the green part imposes thermal treatments under reducing atmosphere, in order not to oxidize the metal [5], [20].

The elimination of organic component from the stereolithography paste is total at about $600^{\circ} \mathrm{C}$ (Figure 8.a)).

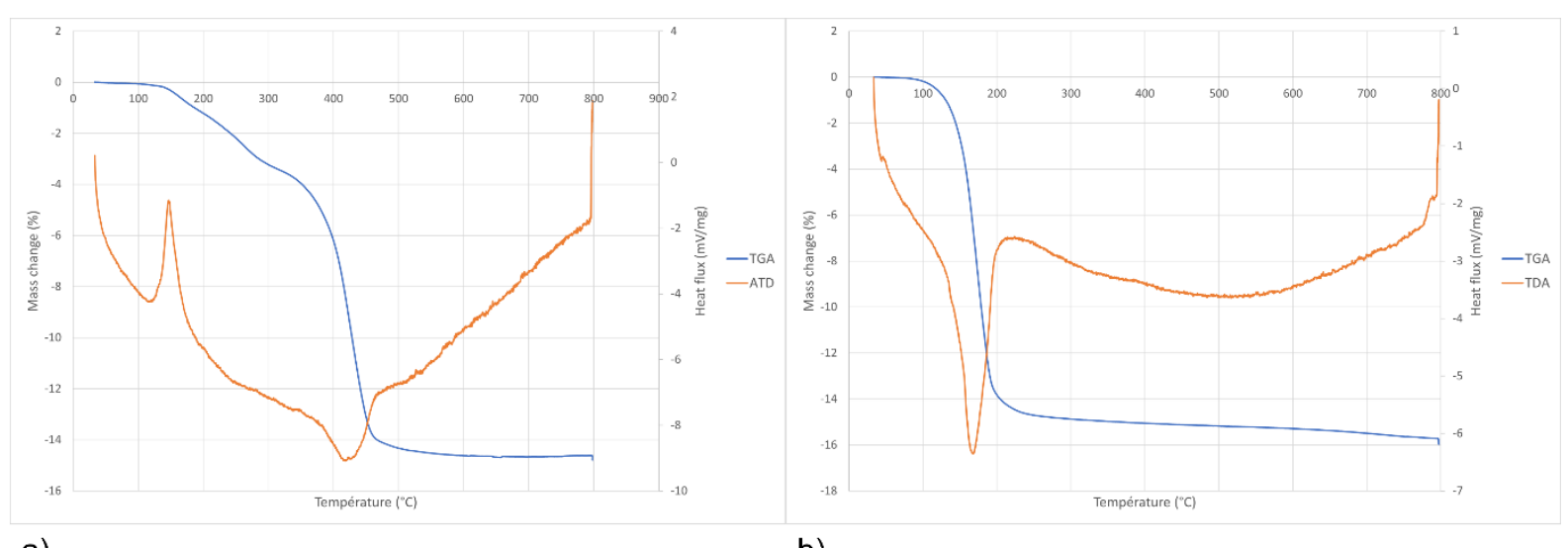

a)

b)

Figure 8: TGA/DTA of the alumina stereolithography paste a) and molybdenum ink b) under $\mathrm{Ar} / \mathrm{H}_{2}$

The thermal analysis of the metallic ink shows an elimination of organic components around $250-300^{\circ} \mathrm{C}$ (Figure 8.b)).

According to the mass losses of the two systems, the debinding cycle under Ar/ $2 \mathrm{wt} \% \mathrm{H}_{2}$ is defined as a first dwell at $600^{\circ} \mathrm{C}$ for three hours with a slow heating ramp of $0.3^{\circ} \mathrm{C} / \mathrm{min}$. This debinding cycle ensures a correct debinding, but the dark color of debinded alumina substrates suggests the presence of a large amount of residual carbon. The reducing atmosphere, used to prevent oxidization of the molybdenum, is not favorable to the complete elimination of organics. In order to reduce the amount of residual carbon in the sintered part, which can be detrimental to dielectric properties, water was introduced into the $\mathrm{Ar} / \mathrm{H}_{2}$ gas [20]. Water was introduced into the inlet $\mathrm{Ar} / \mathrm{H}_{2}$ gas to lead to various partial pressures of water from 0 (no addition of water), 1150, 2000 and $2850 \mathrm{~Pa}$. 
The amount of residual carbon present in the parts debinded under different water contents was first qualitatively observed (Figure 9), then measured using carbon analysis (Horiba Carbon Analyser - EMIA-321V) (Table 4).

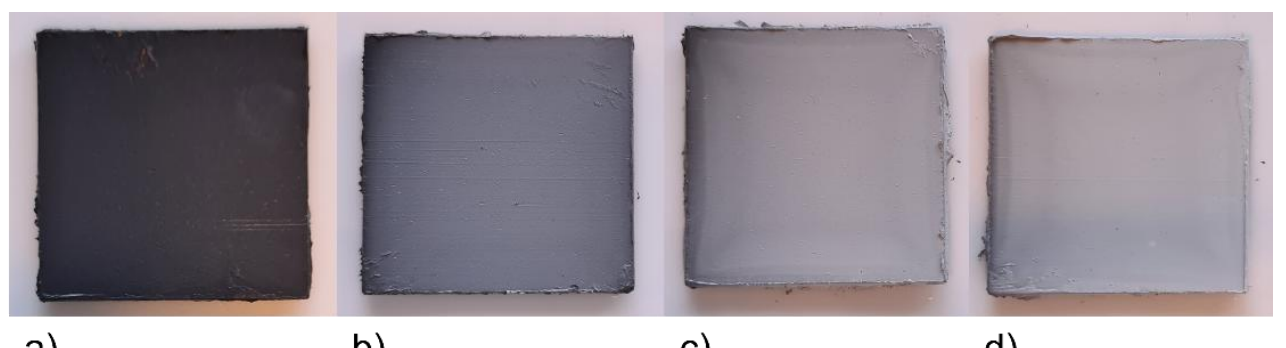

a)

b)

c)

d)

Figure 9: Debinded alumina parts under different moisture contents, O Pa a), $1150 \mathrm{~Pa} \mathrm{~b}$ ), $2000 \mathrm{~Pa} \mathrm{c}$ ) and $2850 \mathrm{~Pa} \mathrm{~d}$ )

Without introduction of water (partial pressure $=0 \mathrm{~Pa}$ ), the debinded part is almost black (Figure 9.a)). Increasing the amount of water, the color became gray, attesting a decrease of the amount of residual carbon.

Table 4: Residual carbon function of water partial pressure

\begin{tabular}{c|cccc} 
Partial pressure $(\mathrm{Pa})$ & 0 & 1150 & 2000 & 2850 \\
\hline $\begin{array}{c}\text { Mass percentage of } \\
\text { carbon }\end{array}$ & 0.853 & 0.354 & 0.155 & 0.087
\end{tabular}

The debinding under wet reducing atmosphere is efficient to reduce the amount of residual carbon. The amount of residual carbon is reduced by an order of magnitude for a partial pressure of $2850 \mathrm{~Pa}(8530 \mathrm{ppm}$ down to $870 \mathrm{ppm})$.

Nevertheless, the question of oxidation of the metal at such a high relative humidity can be raised. In the literature, Bourgès Monnier et al [21] specified that molybdenum is stable up to $1400^{\circ} \mathrm{C}$ in humid hydrogen conditions.

A pre-sintering step $\left(1050^{\circ} \mathrm{C}-4\right.$ hours $)$ has been added in order to consolidate the green part and allow its easy handling.

After debinding, a second ramp up to $1050^{\circ} \mathrm{C}$ at $0.5^{\circ} \mathrm{C} / \mathrm{min}$ with a four hours dwell is apply to confer a sufficient cohesion to part in order to carry it in the sintering furnace without damage.

The ceramic/metal part is finally co-sintered to fully densify the alumina substrate and confer suitable mechanical and dielectric properties, but also molybdenum tracks and vias to reach a high electrical conductivity. The co-sintering cycle is critical in terms of quality of the 
interface between metal and ceramic. Co-sintering is performed under dry $\mathrm{Ar} / 2 \mathrm{wt} \% \mathrm{H}_{2}$ to prevent oxidization of the metal. The sintering temperature, between 1000 and $1700^{\circ} \mathrm{C}$ has been further defined according to the densification of alumina and molybdenum, the mechanical properties of alumina, the conductivity of molybdenum, and the cohesion of the ceramic/metal interfaces.

\section{I.3.3 Observation of co-sintered parts}

Alumina substrates are manufactured by stereolithography with 50 microns thick layers and molybdenum tracks are printed by robocasting with a 100 microns nozzle diameter.

We consider in a first time, the first geometry, which consists in an embedded track in alumina with another track on the surface (Figure 3.a), Figure 10). After debinding, and sintering at $1650^{\circ} \mathrm{C}$ for two hours, the surface track was observed by SEM (Figure 11).

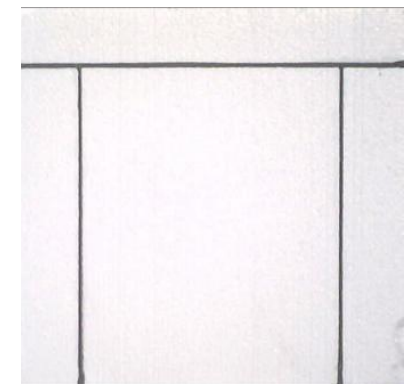

Figure 4 : Surface of the first geometry

a)


Figure 5: Molybdenum track deposited on the surface of alumina, top view a) edge view b)

The track has a width of $150 \mu \mathrm{m}$ and a thickness of $40 \mu \mathrm{m}$. These dimensions are consistent with those expected with a $100 \mu \mathrm{m}$ nozzle (Table 1). The metallic track is continuous, homogeneous and there is no apparent delamination. To check more accurately the absence of 
delamination between alumina and molybdenum, FIB observations were performed on the second geometry (Figure 3.b)).

The ceramic-metal interface was observed in a section drilled by the ion beam (Figure 12)). The metal track is well densified and perfectly follows the profile of the alumina substrate (Figure 12.a)). No delamination is visible. The coefficients of thermal expansion of alumina and molybdenum are close $\left(\mathrm{CTE}{ }_{\mathrm{Al} 2 \mathrm{O} 3}=7 \cdot 1 \cdot 10^{-6}{ }^{\circ} \mathrm{C}^{-1}, \mathrm{CTE}_{\mathrm{Mo}}=5.35 \cdot 10^{-6 \circ} \mathrm{C}^{-1}[22]\right)$, then limiting stresses during cooling from the sintering temperature.

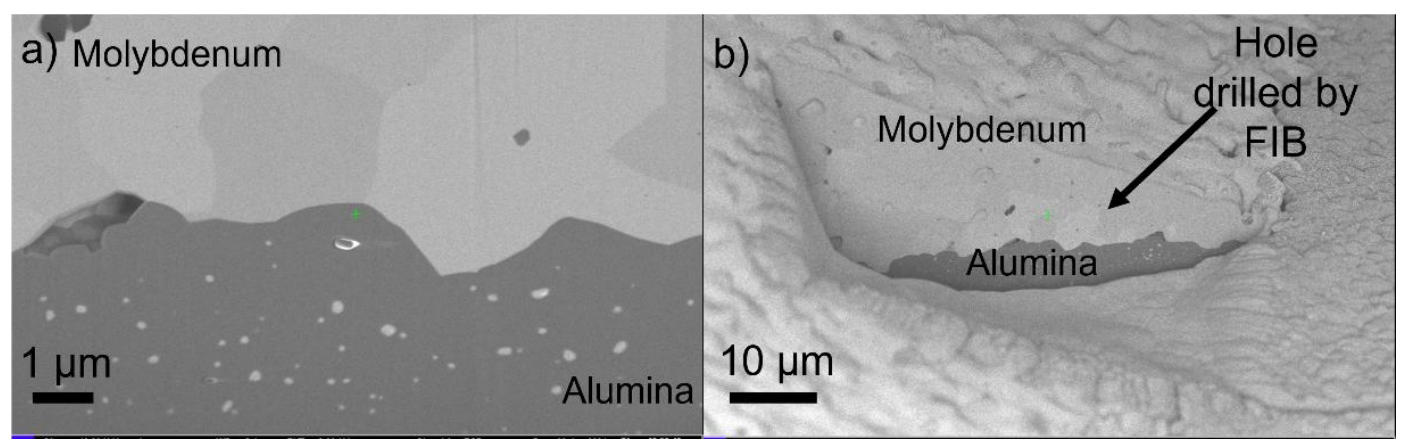

Figure 12: FIB micrographs of alumina/molybdenum interface $\left(1650^{\circ} \mathrm{C}-2 \mathrm{~h}\right.$, backscattered electrons) a) hole drilled by FIB b)

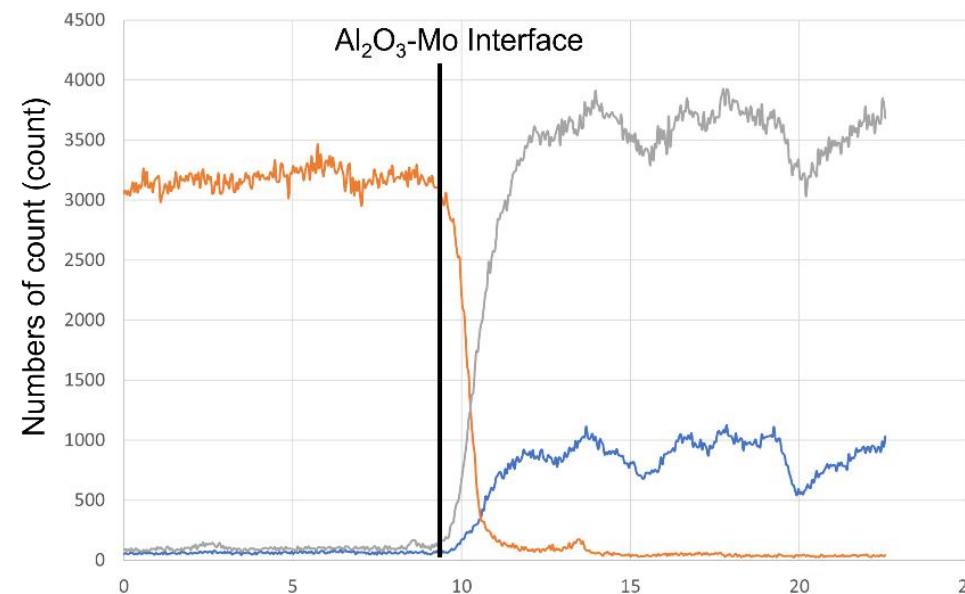

a)

Distance on the profile line $(\mu \mathrm{m})$

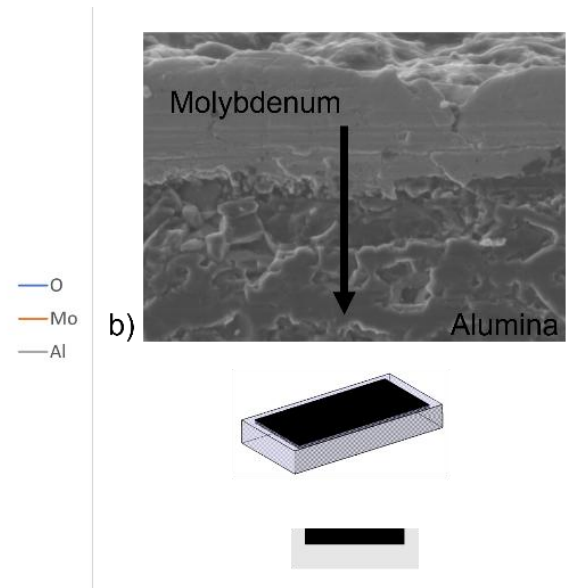

c)

Figure 6: Al, Mo and O profile lines on alumina-molybdenum interface b) studied by FIB on the second geometry c)

The observation of the interface reveals a diffusion of the metal within the alumina but limited to about two microns (Figure 13). Molybdenum is well in its metallic state (no presence of oxygen). Diffusion of molybdenum, even over a short distance, favors a strong interface between alumina and metal. 
The relative density was measured by Archimedes' method on HTCC alumina substrate without molybdenum tracks, sintered at 1600,1650 and $1700^{\circ} \mathrm{C}$ with two hours dwell time (Table 5). The relative density of the substrate reached values larger than $96 \%$ for a sintering temperature higher than $1650^{\circ} \mathrm{C}$.

Table 5: Relative density of $\mathrm{HTCC}$ alumina substrate sintered at $1550^{\circ} \mathrm{C}, 1600^{\circ} \mathrm{C}$ and $1650^{\circ} \mathrm{C}$ for 2 hours

$\begin{array}{llll}\text { Sintering temperature }\left({ }^{\circ} \mathrm{C}\right) & 1600 & 1650 & 1700\end{array}$

\begin{tabular}{l|rrr} 
Relative density (\%) & 92.1 & 96.4 & 97.0
\end{tabular}

\section{I.3.4 Mechanical properties}

The Young's modulus (E) and the flexure strength $\sigma_{f}$ of sintered alumina substrates were measured using the 4-point bending test (Table 6) [23]-[25].

Table 6: Mechanical characterization using 4-point bending test of alumina substrates sintering at 1600,1650 and $1700^{\circ} \mathrm{C}$ for 2 hours

\begin{tabular}{c|ccc} 
Sintering temperature & $\boldsymbol{\sigma}_{\boldsymbol{f}}(\mathbf{M P a})$ & Young modulus $(\mathrm{GPa})$ & Relative density (\%) \\
\hline $1600^{\circ} \mathrm{C}$ & $146 \pm 35$ & $320 \pm 22$ & 92.1 \\
$1650^{\circ} \mathrm{C}$ & $152 \pm 48$ & $335 \pm 16$ & 96.4 \\
$1700^{\circ} \mathrm{C}$ & $206 \pm 26$ & $356 \pm 23$ & 97.0
\end{tabular}

The increase of the sintering temperature leads to an increase of the maximum bending stress, but also of the Young's modulus, which is an agreement with the increase of the density.

\section{I.3.5 Electrical properties}

The electrical resistance of molybdenum tracks is measured for the three co-sintering temperatures (Table 7).

Table 7: Resistivity and section of molybdenum tracks on alumina substrates after co-sintering at 1600,1650 and $1700^{\circ} \mathrm{C}$ for 2 hours under $\mathrm{Ar} / \mathrm{H}_{2}(2 \mathrm{w} \%)$ - Error is defined as the average of the four measurements.

\begin{tabular}{|c|c|c|}
\hline Sintering Temperature $\left({ }^{\circ} \mathrm{C}\right)$ & Electrical Resistivity $(\Omega . m)$ & $\begin{array}{c}\text { Metal track section measured by } \\
\text { image analysis }\left(\mu m^{2}\right)\end{array}$ \\
\hline 1600 & $6.33 .10^{-7} \pm 1.89 .10^{-7}$ & $5.604 .10^{-3} \pm 1.231 .10^{-3}$ \\
\hline 1650 & $4.07 .10^{-7} \pm 6.97 .10^{-8}$ & $3.013 .10^{-3} \pm 0.695 .10^{-3}$ \\
\hline 1700 & $2.04 .10^{-7} \pm 1.24 .10^{-7}$ & $4.248 .10^{-3} \pm 1.377 .10^{-3}$ \\
\hline
\end{tabular}


The resistivity of molybdenum tracks is lower (i.e., higher conductivity) in the case of a part sintered at $1700^{\circ} \mathrm{C}$. Indeed, such a resistivity ensures excellent electrical conductivity for HTCC applications.

According to the various characterizations performed on HTCC components (density, mechanical properties of alumina, electrical properties of molybdenum tracks), the most suitable sintering temperature, is a $1700^{\circ} \mathrm{C}$, two hours. The final thermal cycles (debinding and sintering) are then summarized in Figure 14.

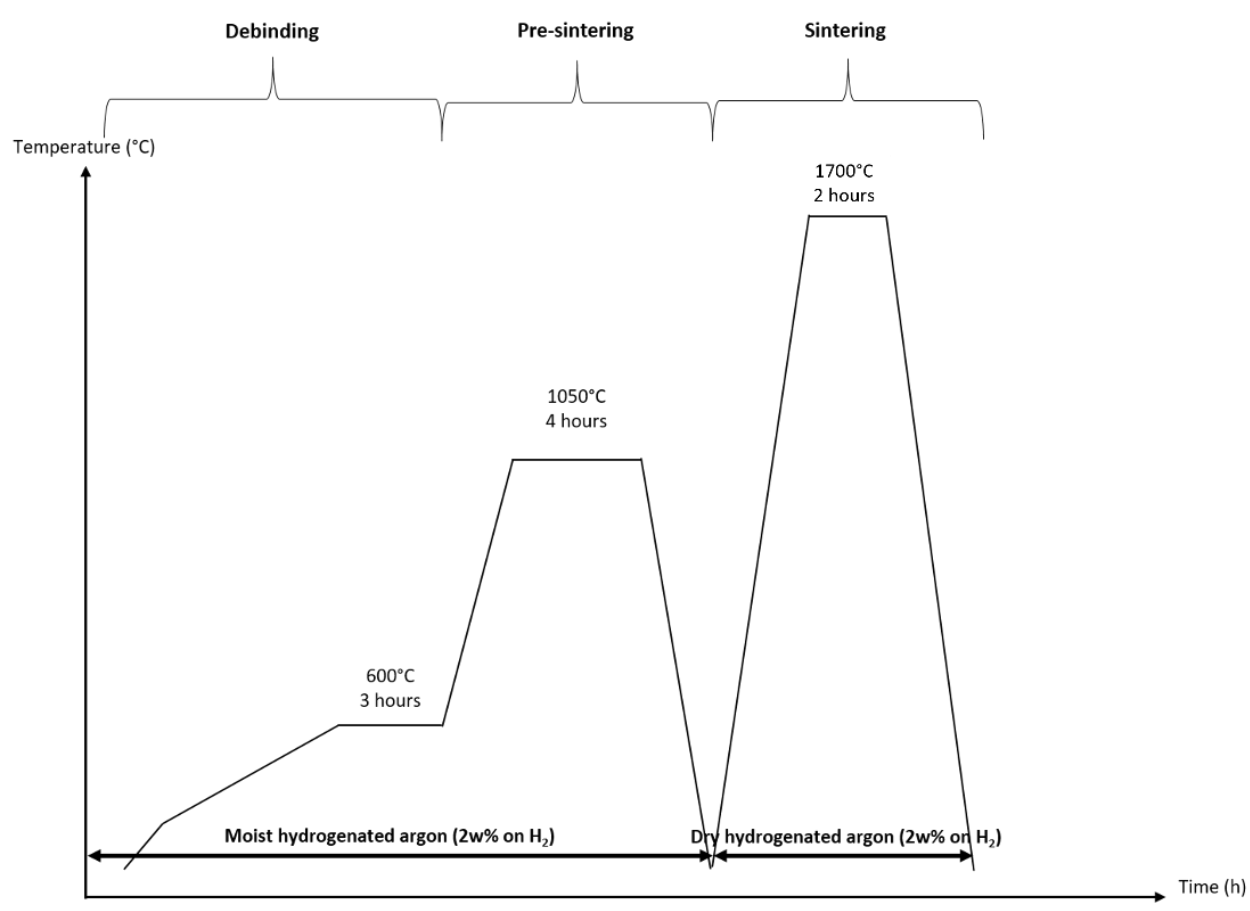

Figure 7: Final thermal cycle with debinding and sintering of HTCC parts alumina/molybdenum

\section{I.3.6 HF properties}

\section{I.3.6.1 Ceramic substrate characterization}

In order to evaluate performances of components at high frequency, HF characterizations of alumina substrates sintered at 1600,1650 and $1700^{\circ} \mathrm{C}$ were performed using the coupled resonator method at $10 \mathrm{GHz}$ (Table 8). This HF characterization method was described elsewhere [26], [27].

Table 8: HF characteristics of alumina substrate sintered at 1600, 1650 and $1700^{\circ} \mathrm{C}$ for 2 hours

\begin{tabular}{c|ccc}
\multicolumn{1}{c}{ Temperature $\left({ }^{\circ} \mathrm{C}\right)$} & Frequency $(\mathrm{GHz})$ & Permittivity $\left(\boldsymbol{\varepsilon}_{\boldsymbol{R}}\right)$ & Dielectric Losses $($ tan $\boldsymbol{\delta})$ \\
\hline 1600 & 9.58 & 8.76 & $2.29 .10^{-4}$ \\
1650 & 9.58 & 8.24 & $3.70 .10^{-5}$
\end{tabular}


According to the literature, these values of permittivity and dielectric losses correspond to a very good substrate (especially at $1650^{\circ} \mathrm{C}$ ), attesting that these alumina substrates are adapted to applications in the domain of hyperfrequency [26], [28]-[33]. The influence of the sintering temperature on the permittivity is not significant. It is difficult to conclude on the lower dielectric losses (one order of magnitude) measured in the material sintered at $1650^{\circ} \mathrm{C}$.

To go further in the characterization of our alumina material in the hyper-frequency range, three specific geometries (Figure 15) were simulated by a digital electromagnetic simulation tool [34]. These geometries are presented in Figure 15 with the corresponding expected frequency response.
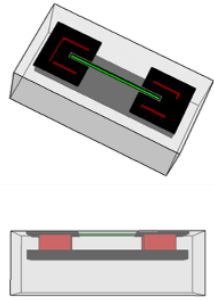

a)

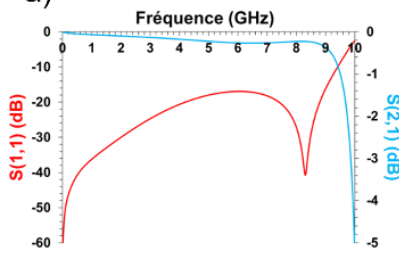

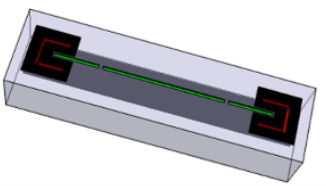

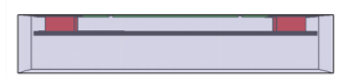

b)

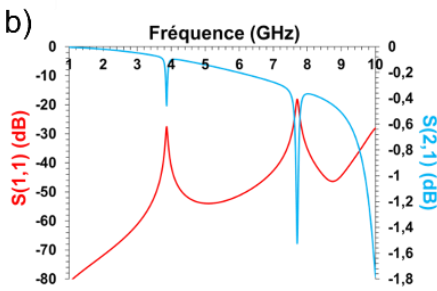

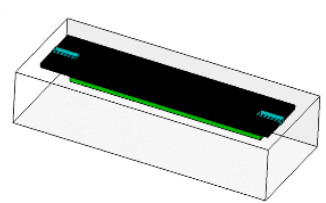
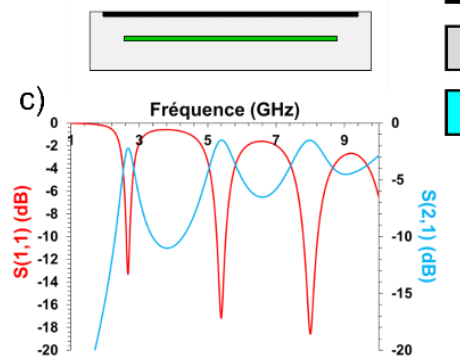

Studied line Mo

Wall Mo

Ground plane Mo

Substrate $\mathrm{Al}_{2} \mathrm{O}_{3}$

Measurement lines

Figure 8: HF geometries and simulations devoted to the characterization of alumina substrates. Transmission line a), Microstrip resonator b) and Embedded microstrip resonator c)

The first geometry called "Transmission line" allows determining the transmission coefficient according to a declination of signal line lengths of three different line lengths. With a transmission coefficient $\left(\mathrm{S}_{21}\right)$ close to $\mathrm{OdB}$, the transmission line has low losses up to about 9 GHz. Beyond this frequency, a matching problem seems to generate a resonance of the system.

The second one is a "Microstrip resonator" used to measure the resonance frequency and resonator quality factor. In the case of the microstrip resonator, there are two resonance frequencies, the first at $3.9 \mathrm{GHz}$ and the second at $7.6 \mathrm{GHz}$. These correspond to two modes when the length of the resonator is respectively half a guided with a transmission coefficient 
$\left(\mathrm{S}_{21}\right)$ close to $0 \mathrm{~dB}$. The line has low losses up to about $9 \mathrm{GHz}$. Beyond this frequency, a matching problem seems to generate a resonance of the system. $(1=\lambda \mathrm{g} / 2)$ and a guided wavelength $(1=\lambda g)$.

The third geometry is an "Embedded microstrip resonator" which limits radiation losses and also allows the characterization of our material in hyperfrequency. The simulation of the integrated microstrip resonator shows three resonance peaks at 2.6, 5.2 and $7.8 \mathrm{GHz}$. As the resonator is embedded in the dielectric, the effective permittivity increases, resulting in a decrease in the resonant frequencies observed in the previous case.

\subsubsection{Elaboration and characterization of hyperfrequency geometries}

The frequency response of the different geometries were characterized using GSG (GroundSignal-Ground) probe measurements. Figure 16 shows the measurement of a transmission line using this principle.

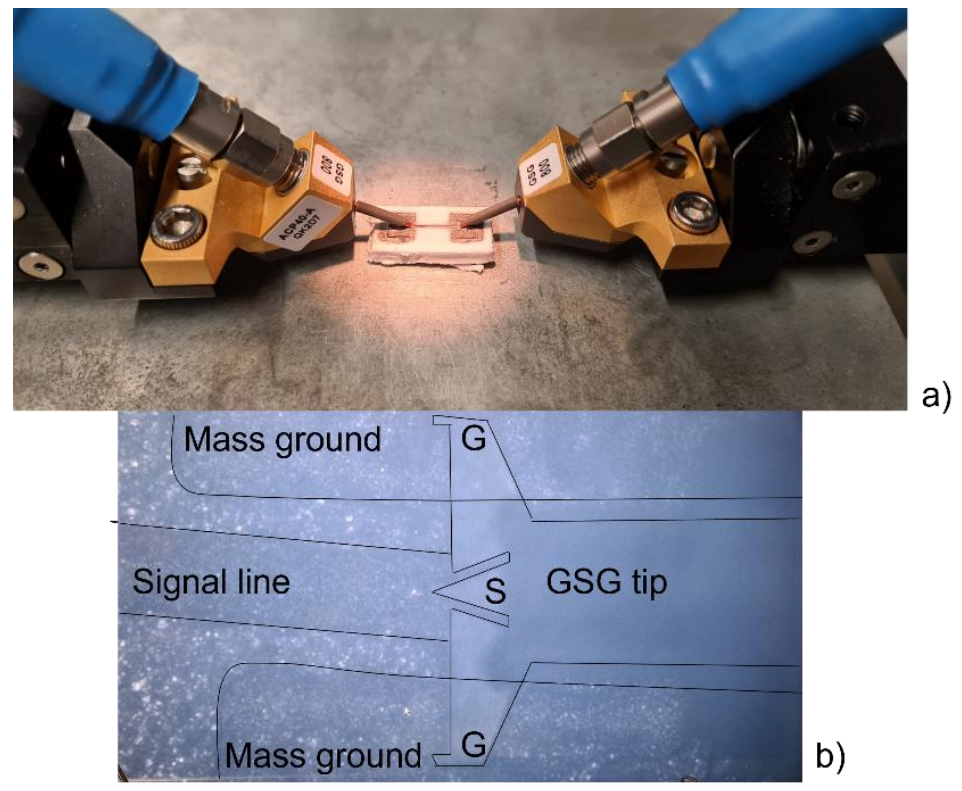

Figure 9: HF measurement of a Transmission line. Process of sub-tip characterization a) GSG tip on the piece b)

The three geometries presented Figure 16 are manufactured using the hybrid additive process that confirms the feasibility of complex metal/ceramic parts by this technology (Figures $\mathbf{1 7 , 1 8 , 1 9 )}$. The dimensions used in the simulation and measured on each fabricated geometry are compared. Each geometry has been characterized up to $10 \mathrm{GHz}$ and compared to the 
simulation in order to evaluate the feasibility of using the developed hybrid machine for the manufacturing of parts usable in the field of hyperfrequencies domain.

A first remark is that the sections of the lines are not constant. The dimensions measured are therefore approximate with a large margin of error. These values are nevertheless given as an indication.

For all three geometries, the transmission lines are thinner and shorter than those used in the simulation, while the gap between the ground planes and the lines is too large. These differences between the simulated ideal pattern and the experimentally obtained pattern are attributed to the precision of the robot driving the robocasting head, which has a resolution of about $20 \%$. These variations in dimensions, between simulations and measurements, will probably lead to differences in frequency responses.

A good frequency response of the transmission line is obtained until about $5 \mathrm{GHz}$, with low losses, lower than $-2 \mathrm{~dB}$ up to this frequency (Figure 17). The resonance observed above 10 $\mathrm{GHz}$ in simulation seems to settle around $9.5 \mathrm{GHz}$ during the measurement. Then, this geometry presents results close to the simulation. The main differences, especially in terms of signal loss, are related to the differences in dimensions.

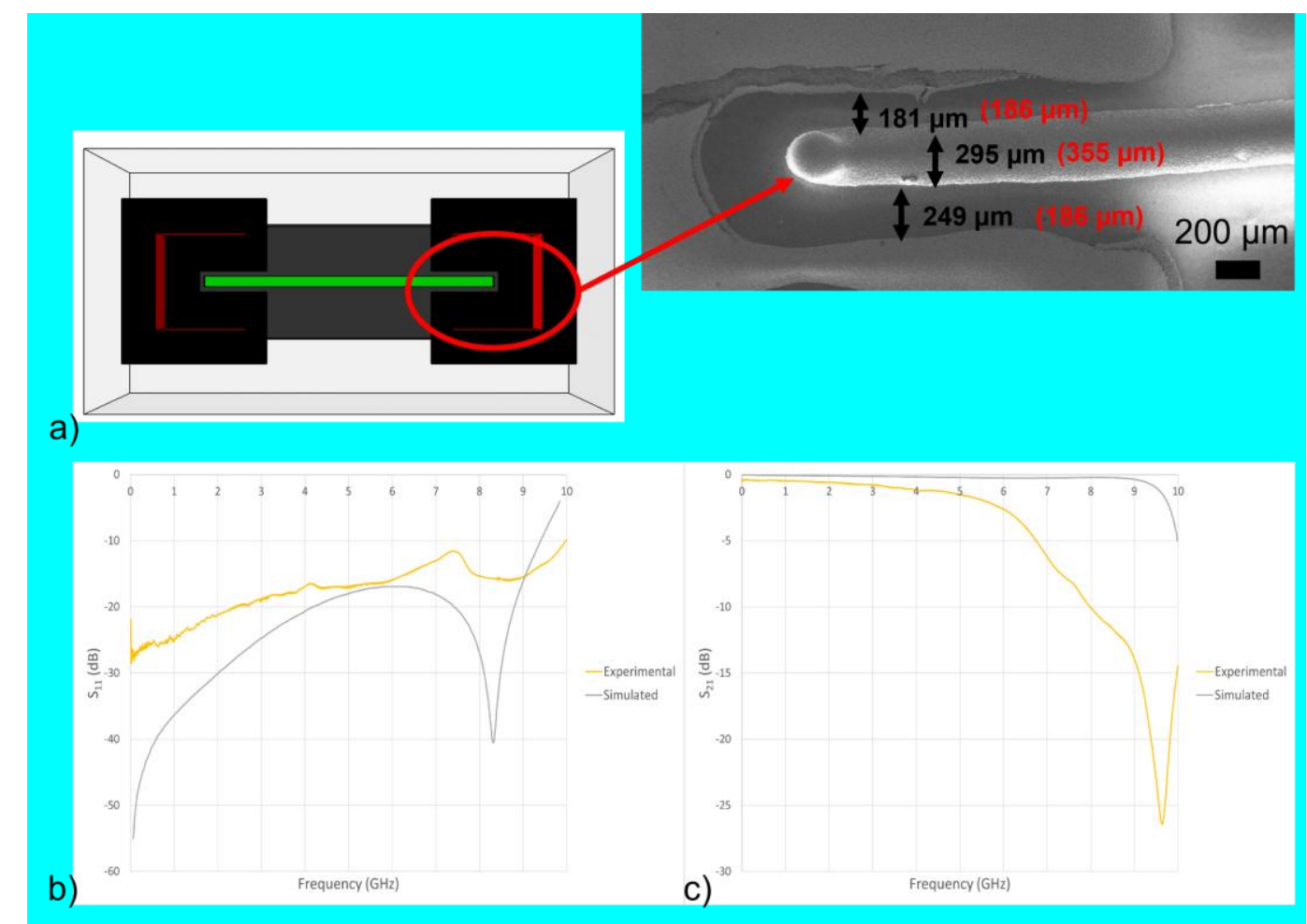




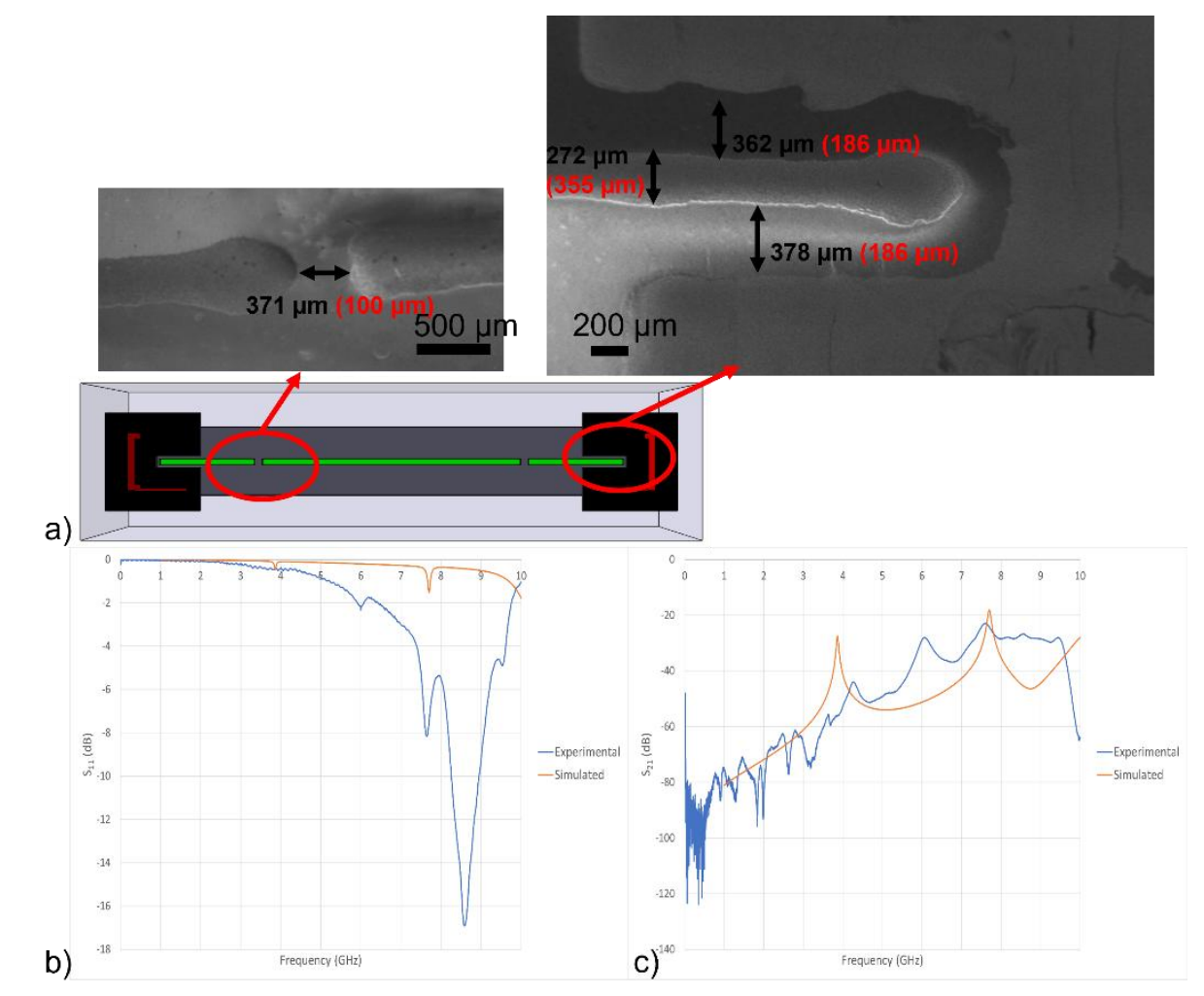

Figure 11: Microstrip resonator with in black the manufactured dimensions and in red the dimensions used on simulation and frequency response a), simulated/experimental comparison with $S 11$ b) and $S 21$ c)

The embedded microstrip resonator presents a resonance close to that of the simulation, but with a shift in frequency (Figure 19). In addition, a doubling of some peaks on the $S_{11}$ is present. In theory, we should have three resonance peaks at 1.8, 4.8 and $7.8 \mathrm{GHz}$, however, characterization shows resonance at 1.9, 4.0 and 5.7 GHz. Once again, the differences are due to the poor precision and different dimensions of the metal patterns. 
a)
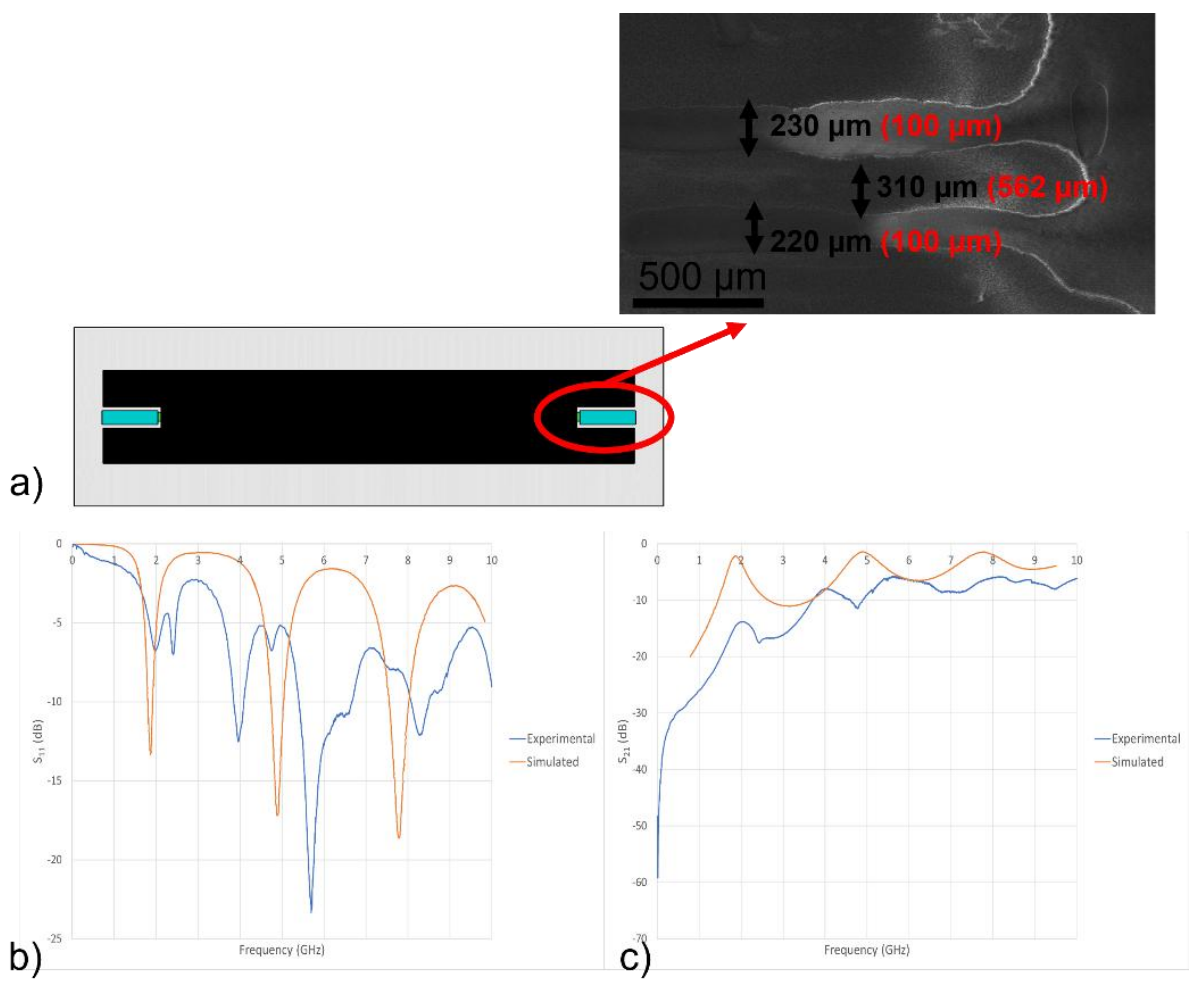

Figure 12: Embedded microstrip resonator with in black the manufacturing dimensions and in red he dimensions used on simulation and frequency response a), simulated/experimental comparison with S11 b) and S21 c)

\section{I.4 Conclusion}

The manufacturing of multi-material parts has been performed using an innovative hybrid additive process. The feasibility of HTCC components composed of alumina and molybdenum, with a 3D metal network, has been demonstrated. The hybrid machine composed of a stereolithography device, allowing the manufacturing of the ceramic dielectric part, and of a robotic arm driving a robocasting head allowing the deposition of the metal, conductive part.

Replacing tungsten used in the previous work ok Raynaud et al. [10] by molybdenum increases the electrical conductivity and offers the advantage to have a CTE closer to the alumina one that limits the risk of delamination.

The thermal cycle, including debinding and co-sintering, was optimized in order to reach a high-density alumina substrate with satisfying mechanical properties and dense non oxidized molybdenum with a high electrical conductivity. The debinding atmosphere was optimized by adding water to the reducing $\mathrm{Ar} / \mathrm{H} 2$ atmosphere. The presence of water drastically decreases the amount of residual carbon within the alumina substrate after debinding. A sintering at $1700^{\circ} \mathrm{C}$ for two hours under a reducing atmosphere lead to a Young's modulus of about 
$356 \pm 23 \mathrm{GPa}$, a relative density of alumina of $97 \%$ as well as an electrical conductivity of molybdenum of $6.10^{6} \mathrm{~S} \cdot \mathrm{m}^{-1}$.

The characterizations in the hyperfrequency domain demonstrate the possibility of manufacturing, using this hybrid additive process, resonators which present frequency responses close to the expected ones predicted by simulation. The main drawback, at this stage of this project, is the poor precision of the metal patterns. Then, the frequency response of the various geometries tested are different to the simulation. The slightest deviation generates an immediate difference in the frequency response. A special attention is currently being paid to the improvement of the accuracy of the metallic network.

This work is co-supported by institutional grants from the National Research Agency under the Investments for the future program with the reference ANR-10-LABX-0074-01 SigmaLIM and from the AID/DGA (Defense Innovation Agency - French Ministry of Defence). 


\section{I.5 References}

[1] C. Robert, «Fiabilité des assemblages de puissance », Thèse de doctorat, Université de Paris-Saclay, 2015.

[2] W. K. Chen, The VLSI Handbook. CRC Press, 2019.

[3] A. Sabban, Novel Wearable Antennas for Communication and Medical Systems. CRC Press, 2017.

[4] A. Julian, «Elaboration by tape-casting and co-sintering of multilayer Catalytic Membrane Reactor- Performances », Université de Limoges, 2008.

[5] J. Raynaud, «Elaboration de pièces 3D multimatériaux par fabrication additive », Université de Limoges, IRCER, 2019.

[6] J. Raynaud et al., "Hybridization of additive manufacturing processes to build ceramic/metal parts: Example of LTCC», J. Eur. Ceram. Soc., oct. 2019.

[7] A. Zocca, P. Colombo, C. M. Gomes, et J. Günster, «Additive Manufacturing of Ceramics: Issues, Potentialities, and Opportunities », J. Am. Ceram. Soc., vol. 98, $\mathrm{n}^{\mathrm{o}} 7$, p. 1983- 2001, juill. 2015.

[8] T. Chartier, A. Badev, Y. Abouliatim, P. Lebaudy, et L. Lecamp, « Stereolithography process: Influence of the rheology of silica suspensions and of the medium on polymerization kinetics - Cured depth and width », J. Eur. Ceram. Soc., vol. 32, nº 8, p. 1625- 1634, juill. 2012.

[9] M. Sealy, G. C. R. Madireddy, R. Williams, P. Rao, et M. Toursangsaraki, «Hybrid Processes in Additive Manufacturing », J. Manuf. Sci. Eng., vol. 140, déc. 2017.

[10] J. Raynaud et al., "Hybridization of additive manufacturing processes to build ceramic/metal parts: Example of HTCC», J. Eur. Ceram. Soc., vol. 41, no 3, p. 2023- 2033, mars 2021.

[11] J.-N. Dody, A. Lefeuvre, et C. Gherbi, «Procédé de fixation hermétique et électriquement isolante d'un conducteur électrique traversant une paroi métallique », FR2717981A1, 29 septembre 1995

[12] T. Chartier, C. Chaput, F. Doreau, et M. Loiseau, «Stereolithography of structural complex ceramic parts », J. Mater. Sci., vol. 37, n 15, p. 3141- 3147, 2002.

[13] Z. Fu, M. Freihart, L. Wahl, T. Fey, P. Greil, et N. Travitzky, « Micro- and macroscopic design of alumina ceramics by robocasting », J. Eur. Ceram. Soc., vol. 37, n 9, p. 3115- 3124, août 2017.

[14] J. Bourret et al., "Micro extrusion of innovative alumina pastes based on aqueous solvent and eco-friendly binder », J. Eur. Ceram. Soc., vol. 38, n ${ }^{\circ}$ 7, p. 2802- 2807, juill. 2018.

[15] N. Delhote, D. Baillargeat, S. Verdeyme, C. Delage, et C. Chaput, « Narrow Ka Bandpass Filters Made Of High Permittivity Ceramic By Layer-By-Layer Polymer Stereolithography », in 2006 European Microwave Conference, sept. 2006, p. 510- 513.

[16] T. Chartier, V. Pateloup, et C. Chaput, «Élaboration de pièces céramiques par fabrication additive », Tech. Ing. Matér. - Verres Céramiques, $\mathrm{n}^{\mathrm{o}}$ ref. article : n4807, févr. 2018.

[17] L. Chen, «Dielectric Performance of a High Purity HTCC Alumina at High Temperatures - A Comparison Study with other Polycrystalline Alumina », 2014.

[18] A. Vasudev, A. Kaushik, K. Jones, et S. Bhansali, «Prospects of low temperature cofired ceramic (LTCC) based microfluidic systems for point-of-care biosensing and environmental sensing », Microfluid. Nanofluidics, vol. 14, n ${ }^{\circ}$ 3- 4, p. 683- 702, 2013.

[19] R. Faddoul, «Optimisation des procédés d'impression dédiés à la production de masse de composants microélectroniques », Thèse de doctorat, Université de Grenoble, 2012. 
[20] A. J. Blodgett et D. R. Barbour, «Thermal Conduction Module: A High-Performance Multilayer Ceramic Package », IBM J. Res. Dev., vol. 26, n 1, p. 30- 36, 1982.

[21] C. Bourgès Monnier, "Propriétés du molybdène et des alliages à base de molybdène », Tech. Ing. Métaux Alliages Non Ferr., vol. base documentaire: TIB357DUO, $\mathrm{n}^{\mathrm{o}}$ ref. article: m565, juin 1998, [En ligne]. Disponible sur: https://www.techniquesingenieur.fr/base-documentaire/materiaux-th11/metaux-et-alliages-non-ferreux42357210/proprietes-du-molybdene-et-des-alliages-a-base-de-molybdene-m565/

[22] J. Reiser et al., "Thermal management materials based on molybdenum (Mo) and copper $(\mathrm{Cu})$ : Elucidation of the rolling-induced evolution of thermo-physical properties (e.g. CTE) », J. Alloys Compd., vol. 776, p. 387- 416, mars 2019.

[23] Y. Khan, «Characterizing the Properties of Tissue Constructs for Regenerative Engineering », in Encyclopedia of Biomedical Engineering, R. Narayan, Éd. Oxford: Elsevier, 2019, p. 537- 545. doi: 10.1016/B978-0-12-801238-3.99897-0.

[24] A. F. Volker Altstädt, « Chapter 8 - Mechanical properties of multifunctional foam core materials », in Multifunctionality of Polymer Composites, K. Friedrich et U. Breuer, Éd. Oxford: William Andrew Publishing, 2015, p. 262- 301. doi: 10.1016/B978-0-32326434-1.00008-8.

[25] P. Forquin et F. Hild, «A Probabilistic Damage Model of the Dynamic Fragmentation Process in Brittle Materials », in Advances in Applied Mechanics, vol. 44, H. Aref et E. van der Giessen, Éd. Elsevier, 2010, p. 1- 72. doi: 10.1016/S0065-2156(10)44001-6.

[26] J. Sheen, «Amendment of Cavity Perturbation Technique for Loss Tangent Measurement at Microwave Frequencies », J. Appl. Phys. - J APPL PHYS, vol. 102, juill. 2007.

[27] S. Mailadil T., «Chapter Two - Measurement of microwave dielectric properties and factors affecting them », in Dielectric Materials for Wireless Communication, S. Mailadil T., Éd. Amsterdam: Elsevier, 2008, p. 11- 47. doi: 10.1016/B978-0-08-0453309.00002-9.

[28] J. Garreau, «Étude de filtres hyperfréquence SIW et hybride-planaire SIW en technologie LTCC », 2012.

[29] K. F. Young et H. P. R. Frederikse, «Compilation of the Static Dielectric Constant of Inorganic Solids », J. Phys. Chem. Ref. Data, vol. 2, n 2, p. 313- 410, avr. 1973.

[30] K. Rajab et al., « Broadband Dielectric Characterization of Aluminum Oxide (Al2O3) », J. Microelectron. Electron. Packag., vol. 5, p. 2- 7, janv. 2008.

[31] D. Gershon, J. P. Calame, et A. Birnboim, "Complex permittivity measurements and mixing laws of porous alumina », J. Appl. Phys., vol. 89, n ${ }^{0} 12$, p. 8117- 8120, juin 2001.

[32] D. Hickson, S. Sotodeh, M. Daly, R. Ghent, et M. Nolan, «Improvements on effective permittivity measurements of powdered alumina: Implications for bulk permittivity properties of asteroid regoliths », Adv. Space Res., vol. 59, août 2016.

[33] M. Tuhkala, J. Juuti, et H. Jantunen, «Method to characterize dielectric properties of powdery substances », J. Appl. Phys., vol. 114, nº 1, p. 014108, juill. 2013.

[34] D. L. Diedhiou, «Étude de dispositifs hyperfréquences accordables en technologie microfluidique », 2012. [En ligne]. Disponible sur: http://www.theses.fr/2012BRES0049/document 